\title{
The Slowdown of the Chinese Economy
}

\author{
Yueqi Song1*, Yiru Wang2*, Zhushan Xiang ${ }^{3 *}$ \\ ${ }^{1}$ Beijing No. 4 High School, Beijing, China \\ ${ }^{2}$ National Junior College, Singapore City, Singapore \\ ${ }^{3}$ Chengdu Shude School International Department, Chengdu, China \\ Email: songyueqi1224@126.com, vincentiniestawangyiru@gmail.com, 2227981988@qq.com
}

How to cite this paper: Song, Y.Q., Wang, Y.R. and Xiang, Z.S. (2019) The Slowdown of the Chinese Economy. American Journal of Industrial and Business Management, 9, 1653-1665.

https://doi.org/10.4236/ajibm.2019.98108

Received: July 4, 2019

Accepted: August 12, 2019

Published: August 15, 2019

Copyright () 2019 by author(s) and Scientific Research Publishing Inc. This work is licensed under the Creative Commons Attribution-NonCommercial International License (CC BY-NC 4.0). http://creativecommons.org/licenses/by-nc/4.0/

\begin{abstract}
We have studied the data representing the change in the Chinese economy and have found that there has been a significant change in the composition of the economy. We have discovered general trends on GDP, Investment and Consumption based on the data and accounted for the unexpected changes during the 1990s period. To account for the decrease in the composition of investment, we have used the Solow model to represent China's development reaching the steady state of the economy. We realised there is a noticeable amount of policies being implemented and we discussed their impacts on the effort to restore the development of the economy.
\end{abstract}

\section{Keywords}

Change in Chinese Economy, General Trend in GDP, Investment, and Consumption, Solow Model, Policies

\section{Introduction}

Witnessing the remarkable changes of China in distinct aspects in the past few years, the economic growth in particular, we discovered that Chinese economic started to reach its slowdown in recent decades. We can see the prominent slowdown of Chinese economic from the recent data of Chinese GDP growth rate. In this paper, we studied the slowdown of Chinese economy through chasing down the general trend of Chinese economy in the past 50 years and spying the reasons for the slowdown. We analysed the data of China's GDP growth, investment, and consumption respectively from the year 1960 to the year 2017. We further explained the decreasing trend in GDP growth rate in 1990s. Generally, we concluded five reasons that could account for the economic trend in 1990s.

1) The turning point of new-birth control in 1991, ${ }^{*}$ Co-first authors, Sort alphabetically by last name. 
2) The transformation of economy in China in 1995,

3) The return of Hong Kong in 1997 and the return Macau in 1999,

4) The financial crisis in 1997 ,

5) The policy driven by Chinese government: soft landing.

Then we found out that the slowdown in Chinese economy growth is driven by the decline in investment, which makes sense from the point of view of the Solow model. Then we collected 5 reasons to cope with the current situations of the steady economic in China.

1) The Belt and Road,

2) Encourage people to start up business,

3) Change in the family planning,

4) Develop the rural areas,

5) Encourage Technological Innovation.

According to the Chinese GDP, China is now the second largest economy in the world, the bellwether of the world economy, playing an integral and crucial role in the world economy development. Determined to provide the causes of the slowdown of Chinese economy and solutions towards this tough situation, we studied the slowdown of Chinese economy and tried to allow the Chinese economy to restrike its engines in the near future. We were expecting that China could continue to have a prosperous economic growth and set the pace of the world economic growth.

In this article, we will analysis the data of GDP, investment percentage, consumption percentage, and populations, make a contrast of trend of GDP with those of investment, consumption, and population, try to find out the internal relationship of these issues.

\section{Methods and Materials}

For this project, we use data on gross domestic product (GDP) for the years 1960-2018, consumption for the years 1992-2018, and investment for the years 1950-2018. The data are taken from the World Bank.

\subsection{GDP (as Shown in the Figure 1)}

GDP growth rate: The GDP growth rate in China has increased from 1960 to about 1964. The GDP growth rate in China has started from lower than -25 percent in 1960 to up to 15 percent in 1964 . While the GDP growth started to decrease from around 1964 to around 1966 with growth rates from over 16 percent to lower than -5 percent. According to the data from Chinese State Statistics Bureau, the GDP in China in 1964 was 59.7 billion dollars and the GDP in 1966 was around 76.72 dollars which shows the early slowdown of economics in China. The GDP growth rate in China has fluctuated dramatically for a relatively long period of time in 1970s and almost all the data remained positive. In 1980s, the growth rate has fluctuated more flatly until the GDP growth rate started to decrease moderately from around 1992 to around 1999. The growth rate raised above nearly 14 percent and then decreased slightly and constantly till now. 


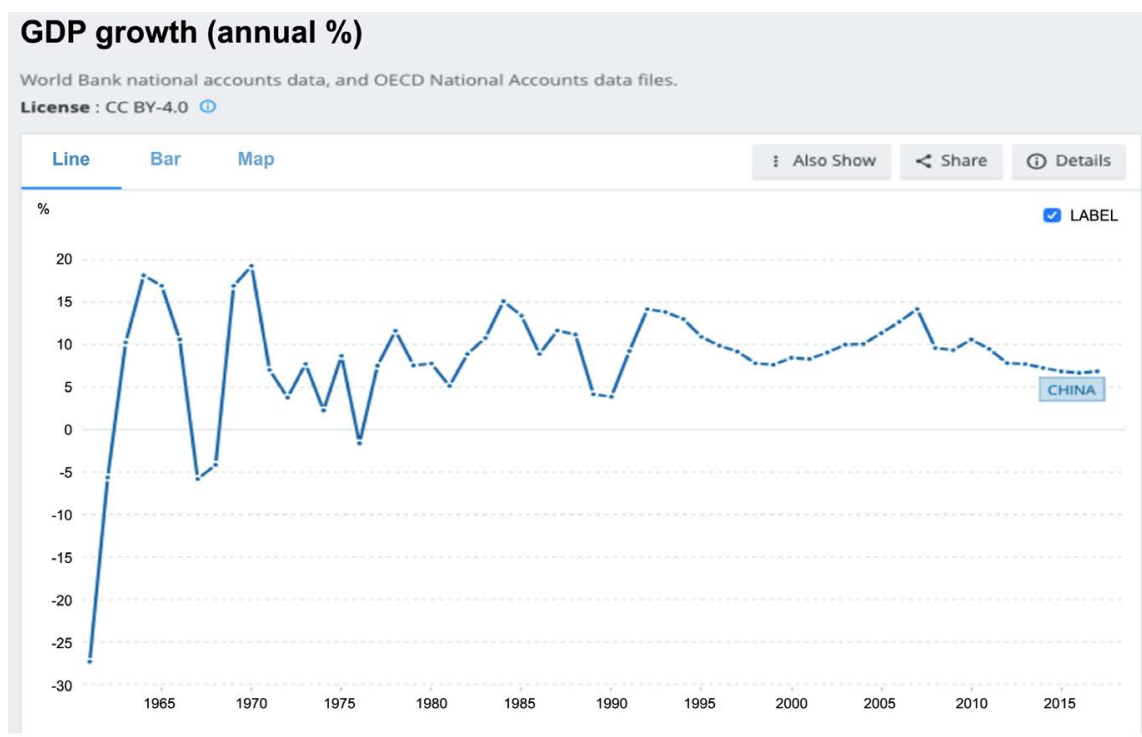

Figure 1. [1] Annual GDP growth rate of China.

\subsection{Investment (as Shown in the Figure 2)}

China's investment accounted for around 22 percent of its GDP in 1953. The investment of China accounted of its GDP has fluctuated from 1953 to about 1957 until the investment ushered in its dramatic increase between 1957 to about 1960. The investment accounted for around 43 percent of China's GDP in 1959 has raised at its highest point within the decade. At the year of 1959 to the year of 1962, China investment of GDP has decreased sharply from over 40 percent to about 15 percent. While the investment of GDP started to increase dramatically after the year of 1962. From 1960s to the beginning of 1990s, the investment accounted for the GDP fluctuated around 30 to 40 percent with its highest point reaching nearly 45 percent in about the year of 1994. While China's investment share of Nominal GDP data began to decrease from nearly 40 percent to lower than 35 percent which is the lowest point within the decade. Then the ratio raised slightly from about 2000 to 2009. Between the year of 2010 to the year of 2018, the data remained relatively stable about 45 percent with a difference of 5 percent. However, it is clear that there is a decreasing trend from 2010 onwards.

\subsection{Consumption (as Shown in the Figure 3)}

Starting from the year 1960, China's consumption of its nominal GDP began to increase significantly from around 63 percent to 84 percent in the year 1962 . However, the ratio started to decrease dramatically after the year of 1960 until the ratio began to raise again in the 1966. Then the data fluctuated from 1970 to 1979 with figures from 64 percent to 60 percent. China's consumption of its nominal GDP then raised slowly, reaching nearly 67 percent in 1983. After 1983, the ratio decreased slightly to 58 percent in 1994 . Then the ratio began to fluctuate around 58 percent to 64 percent between the year of 1992 to the year of 


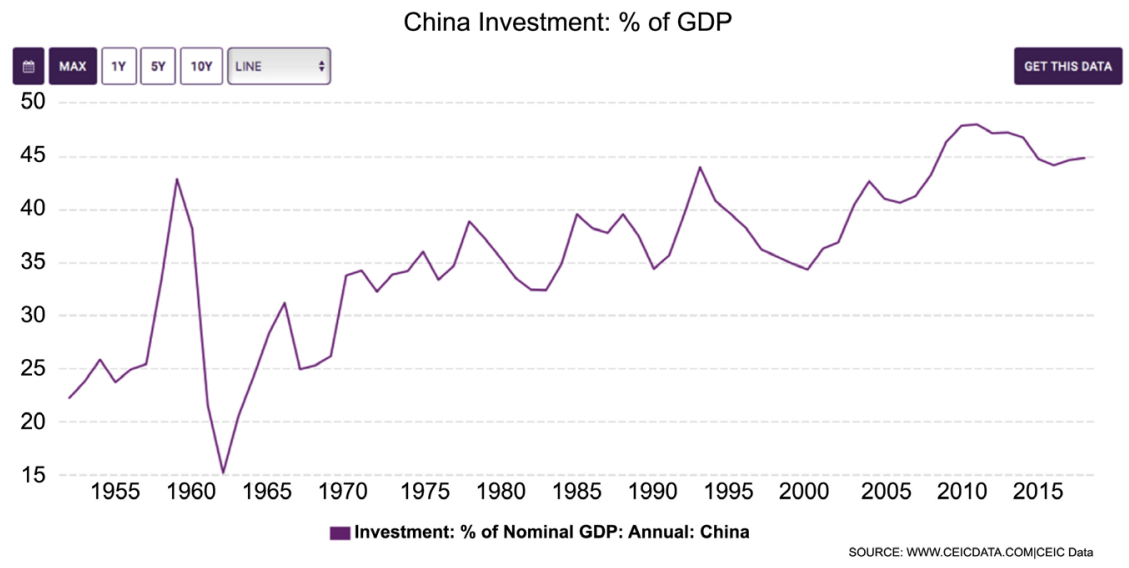

Figure 2. [2] China investment in percentage of GDP.

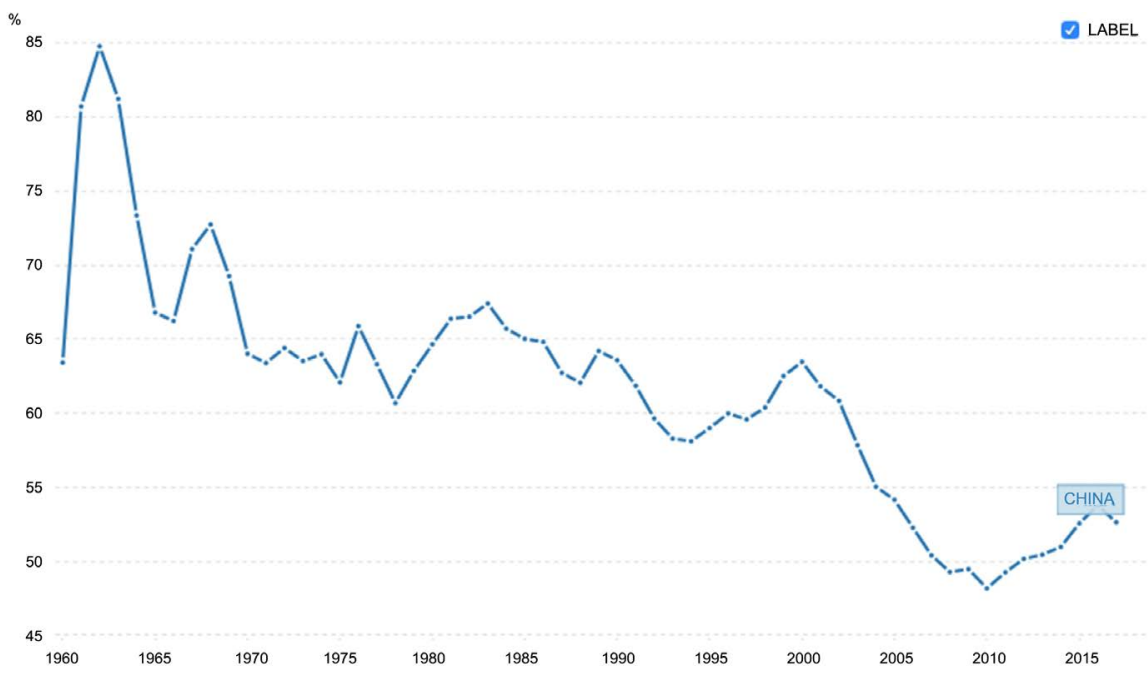

Figure 3. [3] An account of Chinese population trends over the last three decades.

1999. Until the year of 2000 , the ratio reached 63.49 percent which is the apex within the five years. After 2000, China's consumption accounted of its GDP decreased dramatically from more than 60 percent to lower than 50 percent in the year 2010. After the year 2010, the ratio began to increase slightly and gradually headed above 50 percent. Until the year 2016 when the ratio reached around 53 percent, China's consumption accounted of its GDP began to decrease.

\section{Results and Discussion}

\subsection{The Impact of Family-Planning Law Enforcement on Chinese Population Growth}

Figure 4 includes two graphs. The first depicts China's population growth between 1950 and 2017. The second depicts the birth rate between 1982 and 2001. By comparing these two graphs side-by-side, one can determine that the population growth rate and the birth rate increased between 1986 and 1990 and sharply decreased between 1990 and 1992. Further, the rates continued to decrease into 


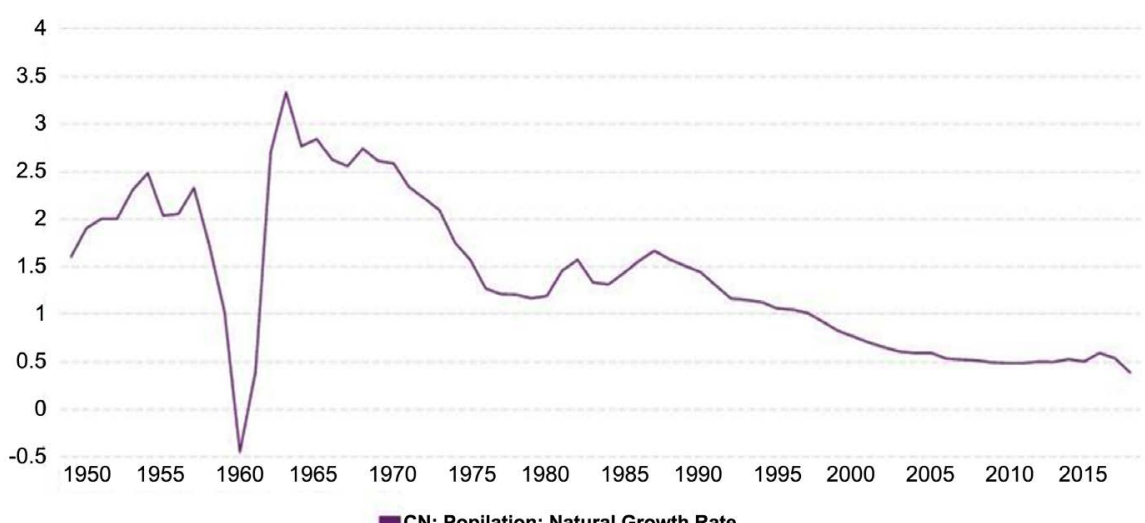

CN: Popilation: Natural Growth Rate
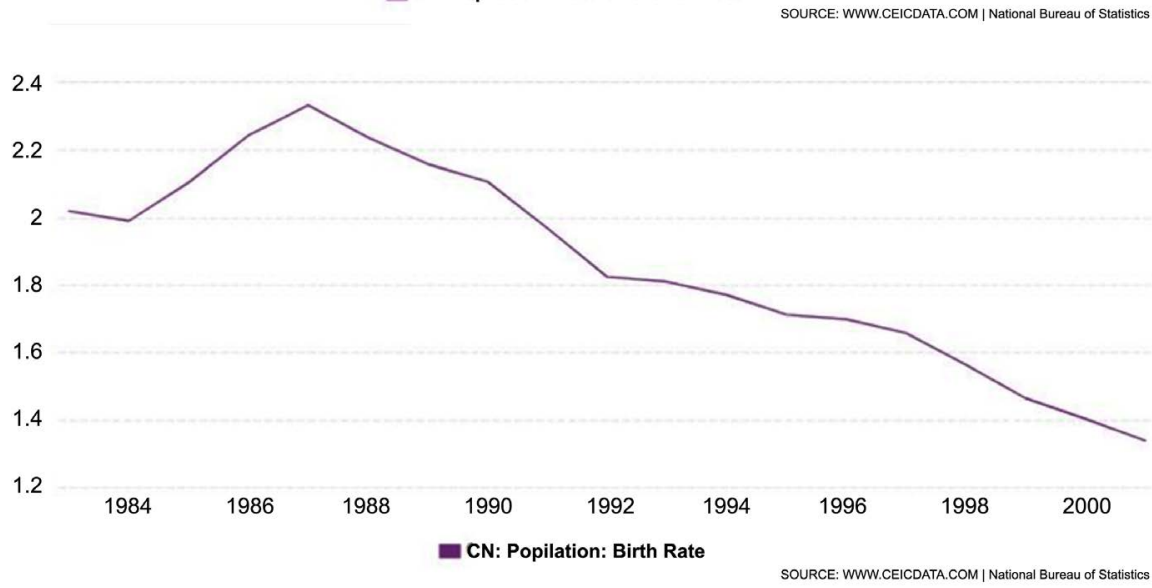

Figure 4. [4] Population-growth and birth rates in China.

the new millennium. These graphs beg to question what occurred around the turn of the 1990s to affect these changes in population growth and birth rate trends.

This paper will argue that China's family planning policies led to these trends, and it will further explore the relationship that these developments have shared with the country's economy. Family planning has been a part of Chinese national legislation since 1982, when laws were passed stipulating that every family could have only one child. At the time, however, the punishment for violating this law was not sufficiently stringent to dissuade wealthy families from taking it seriously. Another unintended consequence of this law related to the fact that Chinese society tends to prize boys over girls, leading families to continue to have children until a boy was born. Richer families that could afford the punishment and expense of having multiple children would either raise multiple kids at once or send the other girls to other families that could not conceive. Tragically, poorer families would discard girls in the woods or otherwise kill them. The overall rate of newborns therefore did not decrease after China first institute the family-planning law. Between 1990 and 1992 [5], however, the Chinese government began to crack down on violations of the policy. Existing Mothers who were caught as pregnant with another child were forced to undergo abortions. The birth rate then began to decrease sharply, leading to the trends 
explored in Figure 4.

Between 1989 and 1991, the Chinese economy experienced a slight downturn, as it in Figure 5, which may be attributable to the sudden changes in population-control law enforcement. However, the overall trend in long-term economic growth as measured by GDP per capita through the 1990s was upwards, which could be due in part to decreases in population growth and birth rate. The relationship between these trends-China's economic growth coupled with decreases in population growth and birth rates-is interesting to explore due to the Japanese case, in which GDP growth rate remained stable even with a decreasing population growth rate. The Japanese experience is reflected in Figure 6.

\subsection{The Economic Trend in China}

\subsubsection{The Transformation of the Chinese Economy in 1995}

China experienced amazing growth after the establishment of the common economy, or public ownership of economic means of production. However, this growth was short-lived because public firms were monopolies that forfeited their profits to the government curtailing innovation in technology and discipline in management. These firms began to rely on government subsidies to operate, and the GDP growth rate began to slow around 1992.

During the Fifth Plenary Session of the Fourteenth Central Committee of the Communist Party of China in September 1995 [8], the state council planned a
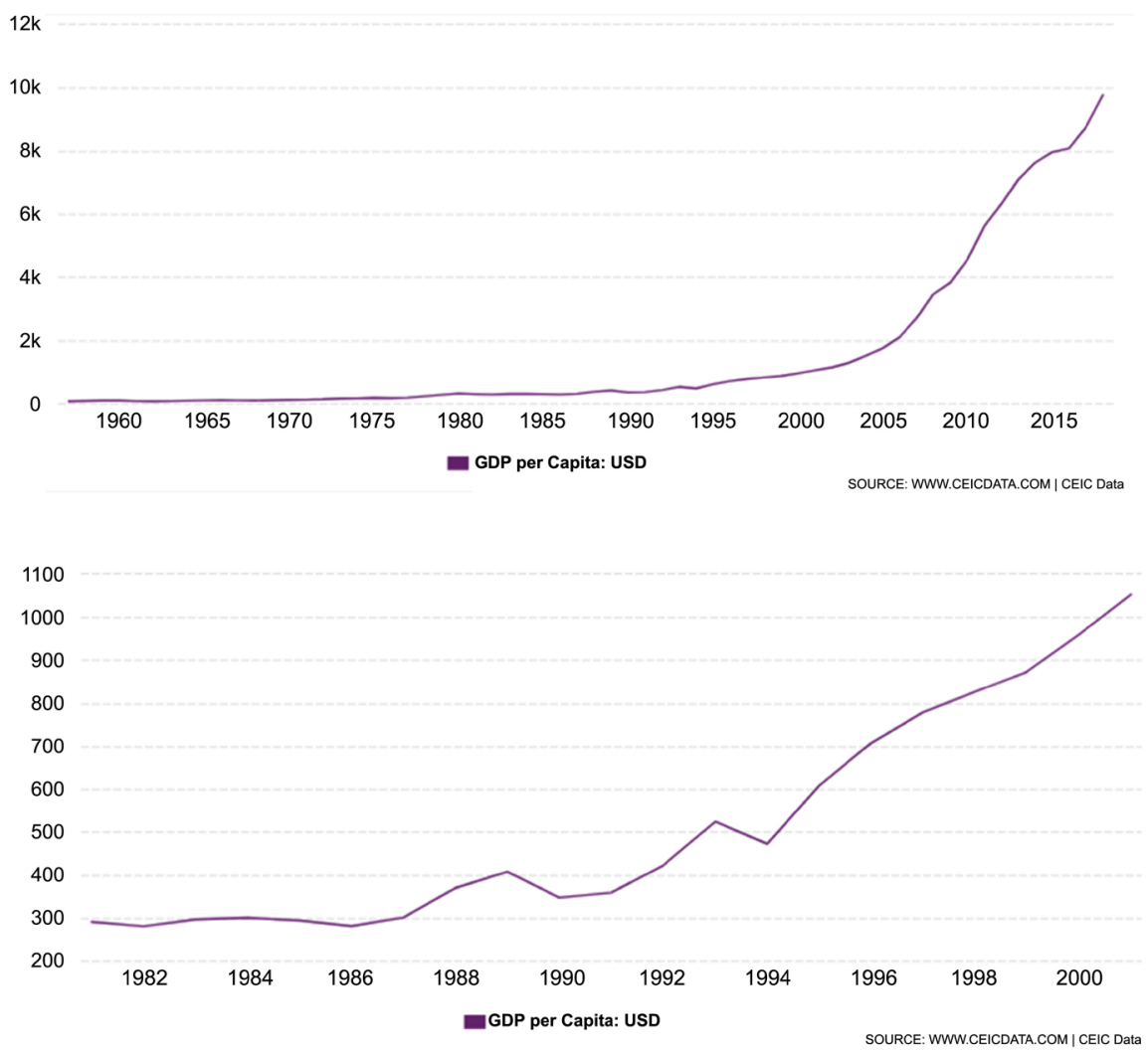

Figure 5. [6] Trends in Chinese GDP since 1955 emphasizing 1980-2000. 

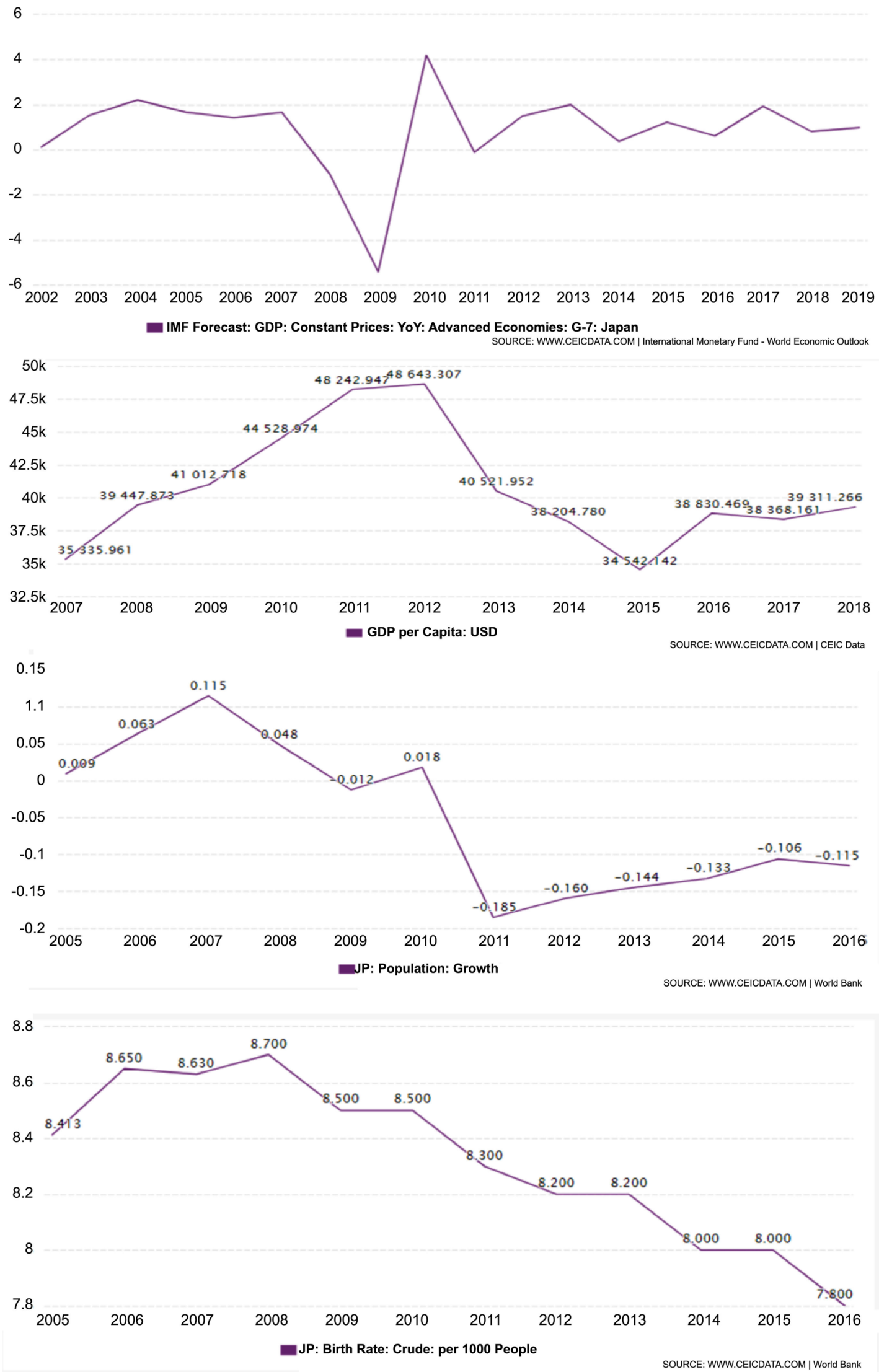

Figure 6. [7] Japan's economic and population trends in the $21^{\text {st }}$ Century. 
reform of the economic system in order to "retain the large, release the small," which meant to retain ownership of major public enterprises while relaxing control over smaller ventures. The council assumed that these movements, which were referred to as aspects of a control right transfer (CRT), would push mid-to-small-sized enterprises into a competitive market.

This decision marked a turning point in the Chinese economy. Instead of organizing a fully planned economic system, the country began to introduce aspects of a free-market approach as well. This may have led to some initial instability, as the decision caused a ripple through the entire world, and political activists questioned whether the nation was moving away from its principles. GDP growth and consumption rates continued to slow in the short-term; however, investment in China began to increase, signaling a great deal of newfound economic potential in the country after the Fifth Plenary Session.

\subsubsection{The 1997 Return of Hong Kong and the 1999 Return of Macau} China regained Hong Kong from Britain in 1997 [9] and Macau from Portugal in 1999 [10]. The financing channels from the international community had been gratefully expanded. The investments from international capital entered China market more easily. It strengthen the ability to withstand risks and to defuse the Asian financial crisis.

\subsubsection{The Financial Crisis of 1997}

The international economy experienced a financial crisis in 1997 [11] due to a confluence of complicated factors, such as the speculative investment activity of George Soros and his companies, the increasing amount of foreign debt on many nations' ledgers that accrued due to a fixed exchange rate system in some Asian country, the financial liberalization around Asia, and the expansion of globalization. At first, China was not greatly affected by the global downturn, but it soon threatened Hong Kong. At this point, the government used a large amount of its foreign exchange reserve to maintain the exchange rate of the HKD, a decision led by Prime Minister Zhu Rongji that aided China weather the crisis. He put capital into the foreign exchange market, and this prevented the RMB from experiencing devaluation and allowed the country to continue to pursue growth through industrial and technological production.

\subsubsection{Soft Landing}

After the economic reforms of 1995 and the subsequent spikes in growth in the late 1990, the Prime Minister enacted a national policy of "soft landing," which represented an attempt to slow down the rapidly growing economy and let it run steadily. The government strictly controlled the issue of currency, raised the deposit interest rate to promote savings, and paid attention to the efficiency of several key markets. In order to decrease the CPI, the government opened the granary to the people, set price floors of grain, and encouraged grain production to stabilize that price. The CPI was lowered to around 4\%, while the GDP growth rate remained at around $8 \%$ [12]. The economy cooled down but achieved a 
more stable rate of increased growth.

\subsection{Use the Solow Model to Explain the Slow down in Economy of China}

To account for the decrease in investment ratio in the GDP, it is predicted by the Solow model. In the Solow model, quantity of labour input, $L$, is constant and there is no improvement in productivity. Thus, all of the action in the Solow model comes from the accumulation of capital, which is governed by two forces: investment (the building of new capital) and depreciation (the wearing out of old capital). At any point in time, the change in the capital stock is the difference between the amount of investment and the amount of depreciation. If I represents the quantity of investment and $D$ represents the quantity of depreciation, then the change in the capital stock is represented as $\Delta K=I-D$. In per worker terms, let $i$ and $d$ be the quantities of investment and depreciation per worker. The equation for the accumulation of capital can now be written as follows: $\Delta k=i-d$. In the case of investment, the assumption is that a constant fraction of output is invested. We denote this fraction $\gamma$ (the Greek letter gamma). This assumption is represented in per-worker terms by the following equation: $i=\gamma y$. In the case of depreciation, the assumption is that a constant fraction of the capital stock depreciates each period. Denote this fraction (the Greek lowercase letter delta): $d=$ $\varangle k$. Combining the three equations, $\Delta k=\gamma y-\varangle k$. The relationship is analysed graphically in Figure 7 [13] which is taken from Weils (2013).

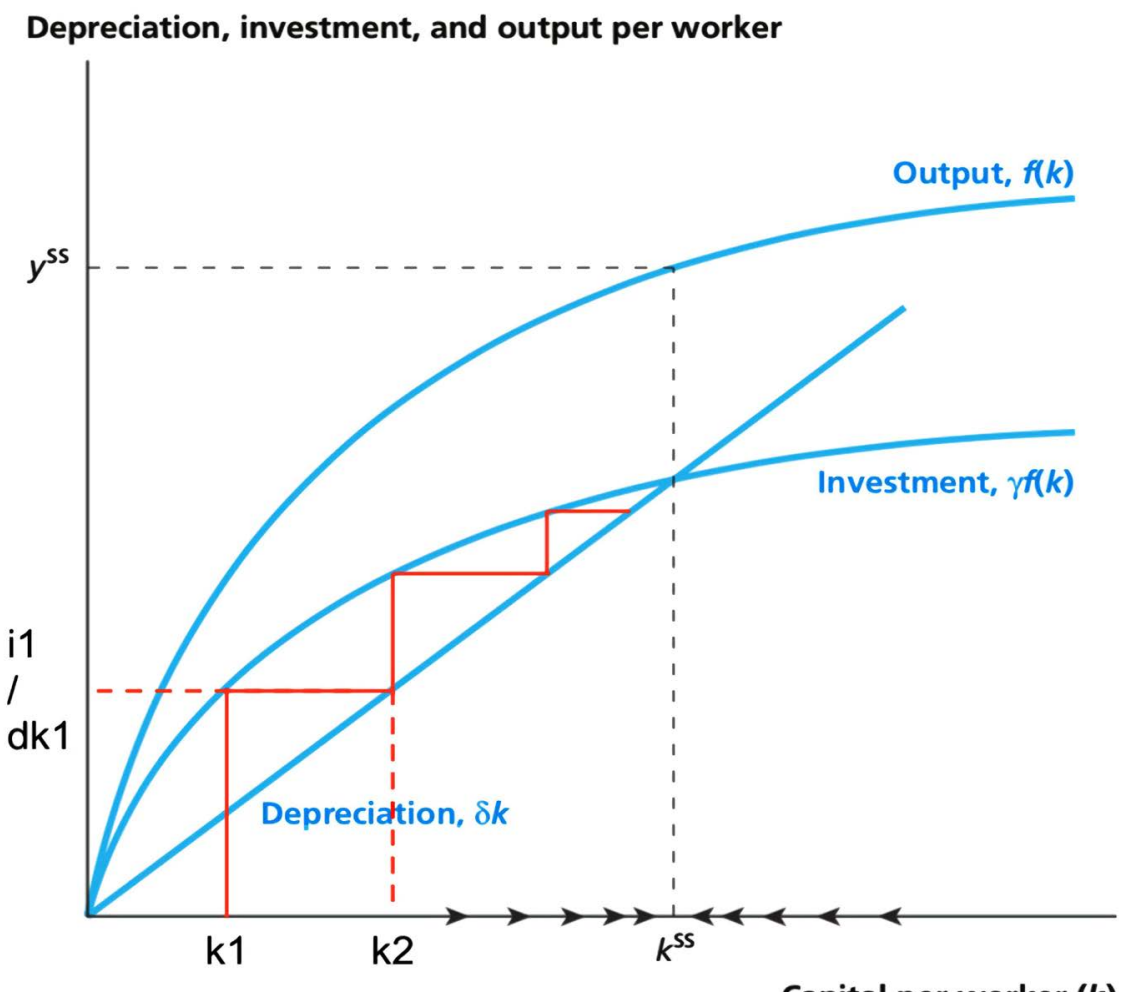

Figure 7. The solow model. 
According to Figure 7, when investment is larger than depreciation, there would be an increase in capital stock; when investment is smaller than depreciation, there would be a decrease in capital stock. This is shown in the movement shown in the graph. In 1960s, suppose China's capital stocks is at the level $k 1$, it requires an amount of investment $i 1$, which corresponds to a depreciation $\delta k 1$. With the difference between investment and depreciation, there would be an increase in capital stocks to $k 2$, for example, in 1980s. As the movement continues, the capital stock will move towards the steady state, noted as $k^{s s}$ in the figure. In the case of Chinese economy, there is a clear decreasing trend of ratio of investment of GDP in the recent decade, this is due to the economy approaching the steady state, where output is bounded by the capital accumulation at a level of $y^{s s}$ noted in the graph. Further increase in investment will only result in higher depreciation which will ultimately lead to a decrease in capital stock, unless the ratio of investment of the output is increased. However, in the long run, the output level will still be restricted by a new $k^{s s}$ and $y^{s s}$ level. Hence the Chinese government decided to switch its focus of development onto other components of aggregate demand (AD).

\subsection{Summary}

The slow down of Chinese is complicated and can't be concluded with merely several factors, but the carry out of family planning, economy transformation, return of Hong Kong and Macau, the financial crisis, and the soft landing are certainly significant on different scales while considering the 1990s.

The general trend for the development of the Chinese economy can be predicted with the Solow Model as the change in economic growth due to capital accumulation was the main driven factor for the growth. However, with the change in composition of the economy and advancements in technology, the patterns of the economic growth may vary from the model in the future.

\section{Conclusions and Remarks}

This paper has conducted research into the governmental, social, and economic policies that have affected China's economy since the early 1990s in order to explain the general economic slowdown that the nation has experienced. The confluence of complicated factors should remind us that no single factor alone can explain this phenomenon. Tools like the Solow model can be used to tease out underlying aspects of the global economy and help policymakers restore the liveliness to Chinese GDP growth. Some of the existing policies that have been proposed or implemented to try to address the economic slowdown, as well as this paper's recommendations, are elaborated below.

\section{1) The Belt and Road}

The Belt and Road is an initiative proposed by Xi Jinping, Chairman of China. The Belt and Road is designed to increase international trade and promote cooperation among China and other countries along the Belt and Road. China en- 
larged its investment into working with Belt and Road countries by $18.2 \%$ [14] in 2015 and signed $42.6 \%$ more service outsourcing contracts with such countries, two policies that might improve the Chinese economy.

\section{2) Encourage People to Start Up Businesses}

In the Chinese labour market, supply always exceeds demand, leading to an unemployment rate about 5\% [15]. To address this issue, the government decided to encourage people to start up new businesses, which would theoretically help relieve the tension of the labour market and create more job opportunities. The government incentivizes this activity by constructing an advantageous market atmosphere for micro-enterprises to enter. For instance, the government promotes fair competition and eliminates local protectionism, subsidizes micro-enterprises, and lowers the tax rate for such businesses. The government also promotes this kind of innovation by creating advertisements that showcase successful entrepreneurs and broadcasting these success stories through public media.

\section{3) Changes in the Family Planning Laws}

The second-child policy failed to foment a population boost after introducing new legislation relaxing the previous family-planning laws.

4) Develop Rural Areas

China possesses a large Gini coefficient (around 0.5 [16]), which means that there is strong polarization between the rich and the poor. In some rural areas, people live subsistence lifestyles, cultivating enough food to survive without contact with the rest of the country. For instance, around Mount Damao in the Tang Xian, Hebei Province, people lived in relative isolation amidst incredible natural beauty. After the government invested in this community and built roads connecting it to other areas, however, more people began to visit and local residents benefited from tourism and other new job opportunities. The economy in Tang Xian now flourishes.

Another problem in rural areas is that some schools don't have air conditioners or toilets, let alone sufficient educational resources like books and teachers. The government must turn its attention toward training more educators, improving their salaries and working conditions, and encouraging them to work in underserved areas through payment or lifestyle incentives. For instance, the government could increase the retirement packages for teachers and invest in improving the conditions of such schools. This kind of investment will safeguard the country's future and promote longer-term growth, creativity, and innovation amongst later generations.

5) Encourage Technological Innovation

Finally, the government should promote innovation in technology. For instance, the government of Beijing built Zhong Guan Cun as an area to promote growth by protecting intellectual property and enlarging investments in technological resources and experimentation. Such policies also promise to herald new developments that could be boons to the national economy. 


\section{Acknowledgements}

We would like to show our deeply gratitude to our supervisor, Pablo A. Guerron, a famous professor who has provided us with much valuable guidance for writing of this paper. And we would also like to give our gratitude to academic assistance, Yu Jinghui. Our sincere appreciation also does to CIS scientific research for providing us chance to do scientific research.

\section{Conflicts of Interest}

The authors declare no conflicts of interest regarding the publication of this paper.

\section{References}

[1] https://data.worldbank.org/indicator/NY.GDP.MKTP.KD.ZG?end=2017\&locations $=\mathrm{CN} \& \operatorname{star} \mathrm{t}=1961$

[2] https://www.ceicdata.com/en/indicator/china/investment--nominal-gdp

[3] https://data.worldbank.org/indicator/NE.CON.TOTL.ZS?locations=CN

[4] https://www.ceicdata.com/en/china/population-birth-death-and-natural-growth-rat e-life-expectancy/population-natural-growth-rate https://www.ceicdata.com/en/china/population-birth-by-region/population-birth-rate

[5] Attane Isabelle, I. (2002) China's Family Planning Policy: An Overview of Its Past and Future. Studies in Family Planning, 33, 103-113.

https://doi.org/10.1111/j.1728-4465.2002.00103.x

https://www.jstor.org/stable/2696336

[6] https://www.ceicdata.com/en/indicator/china/gdp-per-capita

[7] https://www.ceicdata.com/en/indicator/japan/forecast-real-gdp-growth https://www.ceicdata.com/en/indicator/japan/gdp-per-capita

https://www.ceicdata.com/en/japan/population-and-urbanization-statistics/jp-popu lation-growth

https://www.ceicdata.com/en/japan/population-and-urbanization-statistics/jp-birth -rate-crude-per-1000-people

[8] The 14th National Congress. Beijing Review. http://www.bjreview.com.cn/90th/2011-03/30/content_357540_5.htm

[9] Hand Over of Hong Kong. Wikipedia. https://en.wikipedia.org/wiki/Handover_of_Hong_Kong

[10] Macau. Wikipedia. https://en.wikipedia.org/wiki/Macau\#Government_and_politics

[11] Justin, K. (2019) The Asian Financial Crisis: Causes, Solutions, and Lesson Learned. The Balance: International Investing. https://www.thebalance.com/what-was-the-asian-financial-crisis-1978997

[12] Yuan, C. (1997) The Successful Soft Landing of the Chinese Economy and Its Impact on Asia. International Monetary Fund: Asia and the IMF. https://www.imf.org/external/np/apd/asia/CHEN.HTM

[13] Weil, D.N. (2009) Economic Growth. Third Edition, Pearson Addison Wesley, Boston.

[14] The Belt and Road Initiative. LEHMANBROWN: International Accountants. https://www.lehmanbrown.com/insights-newsletter/belt-road-initiative

[15] https://www.theglobaleconomy.com/China/Unemployment_rate 
[16] Dan, K. (2017) China's Extreme Income Inequality Appears to Be Improving after Decades of Deterioration. Quartz.

https://qz.com/937137/chinas-extreme-income-inequality-appears-to-be-improving -after-decades-of-deterioration 